\title{
Knowledge Identity (KI): A New Approach to Integrating Knowledge Management into Enterprise Systems
}

\author{
Ali Intezari \\ University of Queensland \\ a.intezari@uq.edu.au
}

\author{
Morteza Namvar \\ University of Queensland \\ m.namvar@business.uq.edu.au
}

\author{
Ramin Taghinejad \\ Malek Ashtar University \\ taghinejad_r@yahoo.com
}

\begin{abstract}
Despite the extensive studies about KM over the past four decades, the discipline still lacks a clear and practically comprehensive understanding of how KM can be integrated into enterprise systems. To a high degree, the issue is associated with the ambiguous assumptions taken by organizations about knowledge. Many of the assumptions of information systems theories about knowledge require revision, particularly how knowledge is managed. Conceptualizing knowledge as processed data and information has led contemporary design and implementation of enterprise systems to fail to capture the complexity of knowledge. In this article, we critically examine these views. We argue that the answer to the question as to how and to what extent enterprise systems can support $K M$, depends on the assumptions that organizations take towards the nature and sources of knowledge. To address this question, we introduce the concept of Knowledge Identity (KI) and a model of Enterprise Knowledge Integration.
\end{abstract}

\section{Introduction}

Over the past four decades, there have been intensive discussions about the importance of knowledge management (KM) in organizations. Knowledge has been identified as an essential capital and "the most strategic resource" [1, p. 32], a resource that needs to be effectively managed to enable organizations to adapt to the continuing changes of the business environment and to sustain competitive advantage [2]. In a rapidly changing business environment, with ever-increasing volumes of data and information, the ability of an organization to create, share, and implement knowledge based on this deluge of data and information poses significant challenges. To this end, considerable scholarly attention has focused on understanding how technology, especially information systems, contribute to the effective management of knowledge [3][4][5]. Understanding the importance of $\mathrm{KM}$, many organizations have formulated their strategies and designed business processes to promote knowledge and KM [6][7].

In the information systems discipline, knowledge is treated as a set of processed data and information in what is known as the Data-Information-Knowledge (DIK) pyramid [9]. Although this approach has made a significant contribution to our understanding of knowledge, it fails to capture the complexity and multidimensionality of knowledge and knowledge sources such as social interactions. The vague distinction between knowledge, information, and data in the DIK pyramid blurs the differences so that it is almost impossible to determine whether what is talked about in the KM studies or practices is knowledge, information, or data.

Given that organizational KM initiatives heavily rely on information systems, the non-technological aspects of knowledge that differentiate knowledge from data and information are often omitted in the design and implementation of enterprise systems. Examples of these aspects are that knowledge is personal and embedded in people [10][11] and that knowledge engages human context [12] and community [13]. We further discuss these aspects later on in this article.

Despite the overwhelming popularity of $\mathrm{KM}$ discourses and practices among academics and practitioners, one major omission in the extant literature is that how the assumptions taken by organizations towards the nature and sources of knowledge influence the design and implementation of information systems to manage knowledge. This is a significant oversight from both theoretical and practical perspectives. Theoretically, although the nature of knowledge has been the focus of philosophical discourses for centuries, leading to a diverse range of theoretical and philosophical stances towards the nature of knowledge, most empirical studies about KM continue to draw upon a positivist approach. That is, most studies of KM assume knowledge can be stored, shared, and implemented the same way as data and information are dealt with. The assumption suggests a level of equivalence between information and knowledge, something that is deeply contrary to other notions of knowledge such as an 
embodied quality or knowledge as a social phenomenon. Even more troubling, from a practical perspective, is that organizations are often unclear about their assumptions towards the nature of knowledge. Therefore, KM initiatives in organizations often become limited to the management of data and information. This observation is central to our argument in this article.

This paper aims to provide a theoretical framework that explains the complexity of knowledge in the organizational context, and how KM can be integrated into an organization's existing enterprise system. The research question is: in light of the complexity and inherent differences between knowledge, information, and data, how can enterprise systems be used to effectively manage knowledge in organizations?

To address this question, we introduce the concept of knowledge identity (KI). KI refers to the collective construal that an organization's members have about their previous, current, and future knowledge needs. We provide a critical perspective about the assumptions that underline organizations' practice of $\mathrm{KM}$, and argue how the assumptions influence KI. We adopt Kemmis's [14] critical perspective framework, in that (a) we question the assumptions underlying the subject matter and (b) we focus on a social perspective rather than an individual aspect.

In the following sections, we first discuss the theoretical background. Then we present why knowledge, as presented in the extant literature, may fail to be fully managed by enterprise systems. After that, we discuss how organizations can integrate their knowledge management systems (KMS) and enterprise system. To this end, we introduce the concept of KI, and propose a conceptual model of Enterprise Knowledge Integration that draws upon existing literature and illustrates how KI, knowledge assumptions, and organizational culture can affect the integration of KM and Enterprises systems. We finish with a discussion of the implications of the concept and model.

\section{Literature review}

Enterprise systems are social-technical-ecological systems in that they consist of humans, equipment, and machines, as well as location and site [15]. Enterprise systems principally include applications such as enterprise resource planning (ERP) [16], supply chain management (SCM), and customer relationship management (CRM) [17]. Broadly defined, an enterprise system may include content management systems (CMS), enterprise social media (ESM) [18], enterprise planning systems (EPS), and KMS.

Both the information systems and KM literatures are replete with numerous studies that strive to provide insight into how enterprise systems are, or should be, related to organizational KM. For example, Bollojo et al. [19] propose a conceptual model for integrating KM processes and decision support systems. Their model is excessively based on the concepts of data and information, evidenced by their model representing data marts and warehouses as repositories for knowledge. $\mathrm{Xu}$ et al. [20] present a framework for integrating $\mathrm{KM}$ and ERP in an enterprise information system (EIS). They emphasize that KM systems should be integrated into enterprise systems to increase a firm's competitive advantages. They argue that enterprise systems such as ERP can provide the information platform for capturing, storing, sharing, and innovating knowledge [16]. More recent studies provide new perspectives on the effective integration of KM and enterprise systems by appealing to new phenomena. For example, $\mathrm{Li}$ et al. [20] propose a cross-enterprises framework that incorporates Blockchain to meet the security and distributed requirements for knowledge sharing in manufacturing ecosystems. Others recognize the power of enterprise social networking [21] and enterprise social media [18] as online platforms that can facilitate communication among people in supporting knowledge activities such as knowledge sharing.

Despite these important theoretical and practical endeavors, organizations still find it challenging to manage knowledge via enterprise systems. We argue that the assumptions that organizations make about the nature and sources of knowledge play a critical role in the success or failure of KM systems, as well as how enterprise systems can facilitate the management of knowledge in organizations. To this end, we propose the Enterprise Knowledge Integration model for integrating KM into enterprise systems. Central to the model is the concept of $\mathrm{KI}$.

\section{Knowledge Identity (KI)}

Due to the lack of clarity in the KM concepts [22], there are numerous definitions of $\mathrm{KM}$ in the literature [23][24][25]. For example, Walczak [26] defines KM as "any formal policy or informal personal methods that facilitates the capture, distribution, creation, and application of knowledge for decision making" (p. 331). Whereas, Handzic [8] defines KM as an organizationally specified process through which employees' knowledge is acquired, organized, and communicated, to help employees work more effectively. Bounfour (as cited in $[27$, p. 94]), provides a more comprehensive description of KM: "a set of procedures, infrastructures, technical and managerial tools, designed towards creating, sharing and leveraging information and knowledge within and around organizations". Moreover, some studies focus only on a few knowledge processes such as knowledge generation and application [28], while others consider KM as the management of a wider range of knowledge-related activities including accessing, measuring the value, 
generating, transferring, using, representing, and facilitating knowledge growth [29].

Central to the theoretical and conceptual ambiguity is the lack of consensus about the definition and understanding of the nature and sources of knowledge [30]. First, knowledge is often defined in terms of what constitutes knowledge. For example, "an organized combination of rules, procedures, and information" [31, p. 16]. Such definitions focus more on the component parts of knowledge, rather than the implications of knowledge value or use, or what knowledge has to offer in a specific context. Second, others define knowledge as a personal quality [12] and professional experience [32] that is rooted in an individual's actions, behaviors, and experiences [33]. Third, still other definitions focus more on the application of knowledge and the practices with which knowledge is or should be associated. From this perspective, knowledge is defined in terms of the implications of knowledge and what knowledge is for. For example, O'Dell and Grayson [34] define knowledge as information in action. In the organizational context, the objective of KM is seen to improve decision making and promote organizational performance [35][36]. Melkas and Harmaakorpi [37] and Intezari and Gressel [38] define knowledge as a quality that informs and guides decision making. These three conceptualizations of knowledge are found in many definitions in the KM literature with varying degrees of emphasis.

The multiplicity of knowledge definitions is mainly due to the diversity of assumptions about the nature of knowledge.

\subsection{Knowledge Assumptions: Knowledge in Perspective}

There are four major, and to some degree contradictory, conceptions of knowledge that are used in the KM literature. The conceptions include 'knowledge as an objective understanding', 'knowledge as an experiential understanding', 'knowledge as an intuitive understanding', and 'knowledge as a social phenomenon'. Consistent with Kemmis's [14] critical perspective framework, we examine the assumptions that underlie each conception, and emphasize that knowledge is a social phenomenon and culture plays a significant role in KM.

3.1.1. Knowledge, an objective understanding. The DIK pyramid [9] draws heavily upon the positivist tenets about the nature of knowledge, defining knowledge by making differentiations between knowledge, information, and data [12][40]. This approach proposes that data as the "representation of an object" [41, p. 364], are "a set of discrete, objective facts about events" [42, p. 95] that comprise the foundational component of knowledge [40]. Information is defined as processed data, or data in a meaningful context [43]. Knowledge is then defined as processed and validated information [44].

In an objective understanding of knowledge, the components that construct knowledge can be explicitly identified and managed in isolation from the knowledge holder [2]. In this sense, knowledge can be converted back into information and data. That is, knowledge is not innate, but rather exists outside human beings. Knowledge can be detached from the knowledge holder, computerized, and stored in and managed by information systems. The positivist approach seeks to discover absolute knowledge of a phenomenon [45] and embraces realism and objectivism, where knowledge is independent of the knower and can be generalized to various situations [46]. Therefore, information systems are seen as appropriate mechanisms to manage knowledge in organizations.

However, the DIK conception of knowledge offers an over-simplified understanding of knowledge [47][48]. In fact, the pyramid is an artifact of $\mathrm{KM}$ processes, not a representation of reality [49]. In this paper, we critique that idea that knowledge can be managed through information systems. Our critique of the use of information systems to manage knowledge is not new. For example, Hassell [13] argues that knowledge resides in a physical human being and there is no knowledge outside of experience. Similarly, Markus [50] points out that information systems can only manage explicit knowledge, as opposed to tacit knowledge. Explicit knowledge is the knowledge that can be codified and documented. Tacit knowledge, on the other hand, is embodied knowledge that is difficult to codify and store [51].

The explicit-tacit bifurcation of knowledge extends the KM conception of knowledge beyond a purely positivist approach, to knowledge as an experiential understanding.

3.1.2. Knowledge, an experiential understanding. Knowledge as an experiential understanding is knowledge obtained through experience [51]. To a high degree, this approach is congruent with the empiricist philosophical stance. According to this school of thought, our experience is a substantive source of knowledge [53][54]. That is, knowledge is not simply accumulated information [55] or always explicit. Knowledge is professional experience appropriate for a domain [31]. It is rooted in people's experiences and expertise and used for solving problems [56][10].

This is tacit knowledge [57]. A person's relevant and experience-based knowledge can help generate new solutions [58]. It is 'know-how' knowledge and it is based on unconscious/conscious and reflective analyses of previous observations [97] and/or a recognition of patterns of events [51]. Experience-based knowledge is personally-interpreted information related to one's ideas, observations, and judgments [55]. This knowledge is experiential in that a person can apply what he or she has learned from previous experiences to 
similar or different decision situations in the future. Davenport and Prusak's [12] definition of knowledge reflects this approach: knowledge is "a fluid mix of framed experience, values, contextual information, and expert insights that provides a framework for evaluating and incorporating new experiences and information. It originates in and is applied in the minds of knowers" ( $p$. 5). Experience-based knowledge is developed over time [3] and modified by new experiences. Matthew and Sternberg [57] emphasize that: "Experience-based knowledge is context-dependent and typically develops over time through an interactive learning process of perception, action, and feedback" (p. 530).

In addition to the data and experience, another source of knowledge is a priori knowledge.

3.1.3. Knowledge, an intuitive understanding. Probably the least discussed approach to knowledge in the enterprise systems field is the apriorism school of thought. This is mainly so because knowledge from this perspective is based on an internal process of subconscious analysis and sensing [59] that engages emotion and feeling [59], which makes any attempt to capture knowledge via information systems doomed to failure [13]. Unlike the data- and experience-based approaches to knowledge, which are a posteriori knowledge, a priori knowledge is innate and can be acquired through non-inductive means from a particular source - a priori knowledge or intuition. Intuition is "the capacity to know or apprehend something directly, without any need for a justification, such as rational argument, to support it" [61, p. 31]. According to the naturalistic decision making (NDM) community, intuition is "based on large numbers of patterns gained through experience, resulting in different forms of tacit knowledge" [61, p. 164]. Intuition implies one can know something instantaneously and without conscious effort [63][64]. Intuitions can originate from individual and social learning [65].

Finally, we extend the above discussion by arguing that knowledge is not only a personal perspective, but also a socio-cultural phenomenon that is embedded in social processes and common values.

3.1.4. Knowledge, a socio-cultural phenomenon. According to this approach, knowledge is a socially complex phenomenon, rather than just the characteristic of an individual or a set of stored and accumulated data and information. Knowledge is rooted in social processes in that knowledge develops and manifests itself through human interactions in a societal context. This approach draws upon the post-positivist philosophical stance. According to the post-positivist approach, a person can only imperfectly apprehend reality because (a) the human intellectual mechanism is flawed and (b) phenomena are fundamentally intractable [66]. Since an individual's perception of phenomena around them is fallible, an individual cannot gain a perfect understanding of the issues he/she deals with [67]. Therefore, the best way for employees to create and implement appropriate knowledge is through the context of a community whose members are able, keen, and willing to share knowledge and criticize each other's ideas and knowledge. Social learning theory can explain why social context and interactions can serve as a significant source of knowledge. This theory suggests that people learn from each another, which occurs via observation [68], and learning is very closely connected to culture [69]. Therefore, knowledge is highly situated and contextual [70], and inextricably linked with common values and culture [13].

Organizational culture influences employee behavior [69], and so it plays a crucial role in knowledge processes such as sharing [10]. Organizational culture represents the organization's members' values and beliefs about themselves and their organization, and the way that people actually do things in the organization. Schein [71] defines organizational culture as: "a pattern of shared basic assumptions that the group learned as it solved its problems of external adaptation and internal integration, that had worked well enough to be considered valid, and therefore, to be taught to new members as the correct way to perceive, think and feel in relation to those problems" (p. 9). Organizational culture is directly linked to knowledge and influences KM initiatives through norms and people's values and roles [72]. Without a supportive organizational culture, KM initiatives will not be successful [73].

Cultural patterns originate from personal value systems [74] and can profoundly influence a person's perception of how and to what extent he/she should perform knowledge activities [2]. Nonaka and his colleagues [75][76][77] stress that knowledge is deeply rooted in a person's value system, ideals, schemata, and mental models (i.e., thought world), which are inseparable from the group. According to the theory of thought worlds [78], a person's thought patterns and behavior are influenced by the context of the worldview in which they live their lives.

A thought world is "a community of persons engaged in a certain domain of activity who have a shared understanding about that activity" [78, p. 182]. This definition is very similar to what is known as 'community of practice' in the KM literature. While community of practice emphasizes shared competencies and social collaboration in working on similar problems [79], thought world theory emphasizes knowledge differences. The thought world theory is concerned with what people know ('fund of knowledge'), and how they know it ('systems of meaning') [78, p. 182]. According to the theory, people with different thought worlds make sense of situations differently [80] and, therefore, they cannot easily share ideas. Similarly, they may view one another's central issues as 
esoteric, if not meaningless [81]. In such a context, knowledge is socially constructed and not neutral [82]. Instead, knowledge "emerges as conflicting interpretations and action possibilities are discussed and negotiated among the members of a community" [83, p. 20]. The continuous evaluation and critique of knowledge will eventually filter out and eliminate the knowledge that is of less applicable value.

This fortifies the idea that knowledge is more than a fixed set of data and information, but rather, knowledge is dynamic and evolves [84]. Adopting Langley's [85] process thinking framework, we argue that knowledge is not a fixed phenomenon. The process thinking framework suggests that phenomena are dynamic "in terms of movement, activity, events, change and temporal evolution" [85, p. 271]. Knowledge changes and evolves as one (a) enacts knowledge in different contexts and gains new experiences and insight [10], and (b) discusses and negotiates it with others [83, p. 20]. Understanding how and why knowledge emerges, develops, and or terminates over time is crucial in the effective management of knowledge through enterprise systems.

Accordingly, we define knowledge as a dynamic mixture of objective, experiential, and intuitive understanding that emerges and evolves through sociocultural interactions. Aligned with this definition, KM is a socio-cultural and systematic process of designing and using an organization's technological, cultural, and businesses process infrastructures to facilitate knowledge processes (creation, sharing, and implementation) to create value by improving productivity and decision-making quality. This implies that real KM is not possible without community [13].

Table 1 summarizes the assumptions. Knowledge assumptions are dynamic and may change over time or in response to the knowledge needs of the organization. The assumptions should be seen as complementary, and not contradictory to each other. For example, different departments in an organization may have different assumptions about knowledge. The finance and/or accounting departments may adopt a very strong positivist approach toward knowledge (i.e., defining knowledge as an objective understanding rather than an intuitive understanding). In this case, enterprise systems may be seen as an effective system for managing knowledge through documenting knowledge in forms of data and information. However, if a department or an organization defines knowledge as being rooted in human experience (e.g., customer service or human resources departments), then any attempt to codify and store knowledge as data and information would reduce the contextual applicability of the knowledge. In an organization where knowledge is seen as an intuitive understanding, emphasis should be put more on procedures, processes, techniques, and technologies that facilitate the operationalization of people's intuition and tacit knowledge.

Table 1. Knowledge Assumptions

\begin{tabular}{|c|c|c|}
\hline 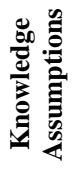 & Key aspects & Definitions \\
\hline 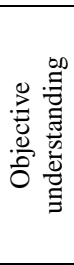 & $\begin{array}{l}\text { - Knowledge } \\
\text { is derived } \\
\text { from data. } \\
\text { - Knowledge } \\
\text { represents a } \\
\text { discrete and } \\
\text { objective } \\
\text { fact. } \\
\end{array}$ & $\begin{array}{l}\text { "Knowledge is to be understood as a } \\
\text { phenomenon that is larger than } \\
\text { information but uses information as its } \\
\text { building material" [86, p. 233]. } \\
\text { "Knowledge is information that has been } \\
\text { authenticated and thought to be true" [55, p. 5] } \\
\text { "Information made actionable" [87]. }\end{array}$ \\
\hline 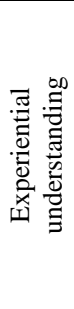 & $\begin{array}{l}\text { - Experience } \\
\text { is a source of } \\
\text { knowledge. } \\
\text { - Experience- } \\
\text { based } \\
\text { knowledge is } \\
\text { know-how } \\
\text { knowledge. }\end{array}$ & $\begin{array}{l}\text { Experience-based knowledge is an } \\
\text { understanding obtained through experience } \\
\text { [52]. } \\
\text { "A fluid mix of framed experience, values, } \\
\text { contextual information, and expert insight } \\
\text { that provides a framework for evaluating } \\
\text { and incorporating new experiences and } \\
\text { information. It originates and is applied in } \\
\text { the minds of knowers" [12, p. 5]. }\end{array}$ \\
\hline 总 & \begin{tabular}{|l} 
- A priori \\
knowledge is \\
a source of \\
knowledge. \\
- Intuitive \\
knowledge \\
\end{tabular} & $\begin{array}{l}\text { Knowing "something directly, without any } \\
\text { need for a justification, such as rational } \\
\text { argument, to support it" }[88, \text { p. } 31] \text {. }\end{array}$ \\
\hline 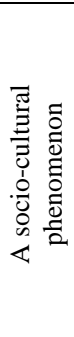 & $\begin{array}{l}\text { Knowledge } \\
\text { is dynamic } \\
\text { and evolves. } \\
\text { - Knowledge } \\
\text { is created } \\
\text { through a } \\
\text { social } \\
\text { process. }\end{array}$ & $\begin{array}{l}\text { Knowledge "emerges as conflicting } \\
\text { interpretations and action possibilities are } \\
\text { discussed and negotiated among the } \\
\text { members of a community" [83, p. 20]. } \\
\text { "The acquisition of knowledge [...] does not } \\
\text { occur in a vacuum. The social context [...] } \\
\text { appears to have an effect on the individual's } \\
\text { acquisition of knowledge. The acquisition of } \\
\text { knowledge, [is] a by-product of human } \\
\text { interaction" [89, p. 381]. }\end{array}$ \\
\hline
\end{tabular}

The knowledge assumptions inform what each department or organization should consider as their KI.

\subsection{Components of KI: Knowledge Heritage, Repertoire, and Aspiration}

Weinreich [38] defines identity as "the totality of one's self-construal, in which how one construes oneself in the present expresses the continuity between how one construes oneself as one was in the past and how one construes oneself as one aspires to be in the future" ( $p$. 80). In the IS context, Carter and Grover [90] define identity as the degree to which one regards use of technology as integral to one's sense of self. In this study, $\mathrm{KI}$ is defined as the characteristic of an organization that refers to the totality of an organization's self-construal, which represents the organization's collective construal of its knowledge heritage, knowledge repertoire, and 
knowledge aspiration. In an organization with a strong $\mathrm{KI}$, people have (a) clear assumptions about the nature and sources of knowledge and (b) an understanding of their organizational knowledge heritage, repertoire, and aspiration. An organization's KI represent the collective construal of its knowledge heritage, knowledge repertoire, and knowledge aspiration.

3.2.1. Knowledge heritage refers to the extent to which an organization's members have a clear understanding of (a) what and how knowledge was created, shared, and implemented in the past, (b) what knowledge was important in the past and why, and (c) what knowledge has disappeared and why. Rather than only dealing with what knowledge has been inherited, knowledge heritage is concerned with how much people are aware of the knowledge that has evolved, survived, or disappeared over time. Are the organization's members aware of any knowledge that is no longer of interest or useful for the organization? What knowledge was necessary and important in the past? Why some knowledge is still used in the organization, and why some knowledge has been overlooked or disappeared?

3.2.2. Knowledge repertoire represents the body of knowledge that exists in an organization at any given point in time. As far as KI is concerned, knowledge repertoire refers to the extent to which an organization's members are aware of (a) what knowledge exists, (b) what knowledge is important/not important, and (c) what knowledge is being created, shared, and implemented at the present time. The combination of the understanding an organization's knowledge heritage and repertoire helps the organization and its members save time and energy by avoiding developing and pursuing a knowledge solution that has proven to be ineffective in the past.

3.2.3. Knowledge aspiration refers to how organizational members construe their needs for knowledge in the future. An organization with a high level of knowledge aspiration encompasses members who have a clear understanding of (a) what knowledge will be available in the future, (b) what knowledge they will need, and (c) what knowledge they would like to have in the future. Knowledge aspiration can inform future recruitment and training programs in the organization.

The role of $\mathrm{KI}$ in the integration of $\mathrm{KM}$ and enterprise systems is explained below.

\section{Enterprise Knowledge Integration Model}

As illustrated in Figure 1, the integration of KM into enterprise systems should be based on an organization's KI. That is, the organizational policies, processes, and methods that facilitate the creation, sharing, and implementation of knowledge should be informed by the organization's KI. Organizations with ambiguous assumptions about what they mean by knowledge, and/or lack an understanding of knowledge heritage, repertoire, and aspiration, are very likely to end up with enterprise systems that are nothing more than data management systems.

Based on an analysis of the data and information availability and needs, enterprise systems can influence the organization's KI by determining what knowledge currently exists and/or will be required for better decision making. For example, what data and information will be needed in the future, and whether the organization has the knowledge required to use and make sense of its data and information?

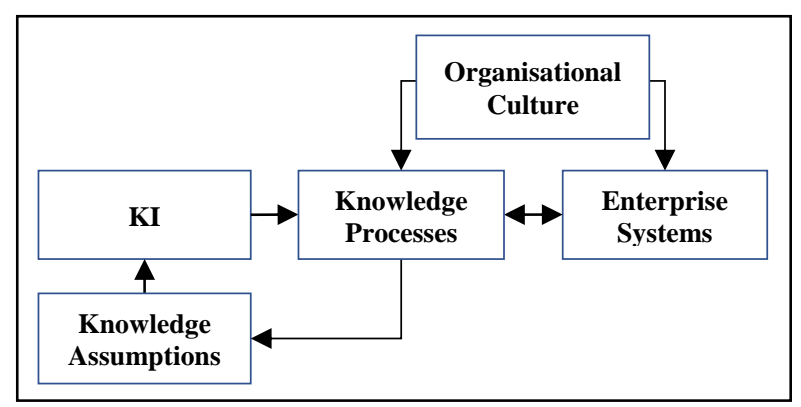

Figure 1. The Enterprise Knowledge Integration model

According to the model of Enterprise Knowledge Integration (Figure 1), organizations need to have a strong KI. An organization with a strong KI enjoys a clear and accurate understanding of their knowledge sources, needs, and activities in the past, present, and future.

The Enterprise Knowledge Integration model is based on the idea that the sources of knowledge are people and information, and they should be managed as inextricably interrelated. Specifically, data must be used in conjunction with human knowledge and reasoning [91]. According to the model, enterprise systems should be seen as a solution that integrates all data and information [42] to support knowledge creation, knowledge sharing, and knowledge implementation. In doing so, enterprise systems can provide features that facilitate both technical and social processes related to the knowledge processes, and these processes can help employees make better decisions and work more effectively. For example, in a multinational company, enterprise systems should support communication among experts, who speak different languages, by providing a Cross-Lingual Knowledge Retrieval (CLKR) system, which "enables the user to search for required knowledge and expertise across a number of sources, which are originally distributed across different languages" [38, p. 82].

It is also important to mention that the knowledge processes are interrelated [2], and therefore KM systems should deal with whole knowledge lifecycles and align them together in order to create business value [92]. 
Moreover, enterprise systems and KM integration should be aligned with the organization's culture, as shown in Figure 1. Organizational culture can support or suppress an organization's capacity and ability to use its knowledge sources [12][93]. Shared values and beliefs towards knowledge activities is a critical component in successful KM initiatives. People's cultural experiences and worldviews affect their knowledge and perception of the phenomena around them. If the organizational culture does not support shared commitment towards knowledge processes, knowledge technologies will not necessarily improve knowledge processes, no matter how advanced the technology infrastructures are [2][94]. The type of information technology that is used in the organization should be aligned with the organizational culture [95], and support the existing social network to support knowledge processes [79].

In short, we agree with Davenport and Prusak, that the goal of knowledge is "to produce insights that drive better decisions" [96, p. 8]. KM creates value when it improves productivity by making knowledge available that enables informed decisions and actions [34][97]. However, not all problems cannot be solved through routine analysis of data and information [98], or necessarily solely through routing applications of extant knowledge [58]. Creating, sharing, and implementing knowledge is not simply a function of codification, storing, and dissemination of data and information; it is a function of the personal and social characteristics of the knowledge itself. That is, employees' social interactions should be supported by enterprise systems that lead to the effective creation, sharing, and implementation of knowledge. Enterprise systems can be helpful only when they are designed and implemented based on an integrative model of the socially complex and dynamic characteristics of knowledge.

\section{Conclusion}

In this paper, we argue that the failure of effectively integrating KM into an organization's enterprise systems is, to a high degree, due to ambiguity in the knowledge assumptions that underlie the organization's KM and enterprise systems. Organizations are often unclear about what they mean by knowledge, and whether what they really want to manage is data, information, or knowledge. The diverse and often contradictory assumptions about knowledge can lead organizations to fail to effectively use the full potential of their knowledge.

We discussed four major assumptions about the nature and sources of knowledge: knowledge as an objective understanding, an experiential understanding, an intuitive understanding, and as a socio-cultural phenomenon. The four assumptions are complementary to each other, in that each may provide a more accurate understanding of the nature and sources of knowledge in different decision contexts, departments, organizations, and industries. From this discussion, we defined knowledge as a dynamic mixture of objective, experiential, and intuitive understanding that emerges and evolves through socio-cultural interactions.

We proposed an Enterprise Knowledge Integration model that outlines the key factors that must be taken into account to integrate KM into enterprise systems. The model incorporates perspectives from epistemological discourses and social identity to develop a theoretical framework of the process by which knowledge can be more effectively managed in organizations. The integration of $\mathrm{KM}$ into enterprise systems is more than just a technological integration problem. Central to the model is the new concept of KI. KI is an organization's self-image, the internalized meanings and expectations associated with the organization's members' beliefs about what should be considered as knowledge. This includes what knowledge was important in the past, what knowledge they need and/or create now, and what knowledge they will need or wish to have in the future. KI determines the importance of the knowledge that is available or needed at any point of time.

According to the model, enterprise systems play a critical role in enhancing the organization's KM capacity and the success of the KM initiatives; however, without having a strong KI, enterprise systems may fail to fully manage knowledge. Knowledge is a socially complex phenomenon. People's engagement in the processes of knowledge creation, sharing, and implementation is profoundly influenced by organizational culture.

This paper contributes to the body of knowledge by providing a comprehensive understanding of the complexity of knowledge and proposing a theoretical framework that can be used for theory development in the IS disciplines. The prevailing approach in the KM and enterprises systems literatures is that knowledge is a personal quality. This paper extends this understanding by conceptualizing knowledge as a sociocultural phenomenon. Moreover, the Enterprise Knowledge Integration model and the new construct of KI lay the foundation for a more nuanced understanding of the nature of knowledge in organizations, and for theorizing on the integration of $\mathrm{KM}$ into enterprise systems. While KM theorists have dedicated substantial scholarly effort to understanding the complexity of knowledge, the prevailing approach to knowledge in the information systems field is the DIK pyramid. Considering knowledge as a higher level of data and information leads to incorrect assumptions for designing and implementing enterprise systems in organizations.

This study also offers a theoretical basis that operationalizes the concept of 'effective use' [99][100] in the IS field. There is still a need for more research about the 
social dynamics of knowledge in the organizational context. We are confident that the concept of KI in the KM and enterprise systems literatures offers a fruitful avenue for future research. Future studies can examine the impact of KI on individual and organizational performance in relation to knowledge creation, sharing, and implementation.

The concept of KI can shed light on the role of KM in the adoption and use of emerging technologies such as Big data analytics and artificial intelligence (AI). KI offers a new framework for both AI developers and end users to develop, implement, and use AI in an effective alignment with existing Enterprise systems.

The Enterprise Knowledge Integration model can provide a practical framework for organizations to better understand the technological and social features involved in KM. In light of the KI concept, organizations and managers may revise their current approaches to their $\mathrm{KM}$ initiatives and the use of enterprise systems in managing their knowledge. Organizations can conduct surveys to identify the level of KI across the organization, at different managerial levels or in different departments. These investigations can help organizations assess whether individuals and groups in the organization truly understand their knowledge needs at the individual, group, and organizational levels at any given point in time. KI assessment helps organizations start thinking through who they are (what they know) and what their knowledge purpose (what they need to know) is.

To conclude, we strongly suggest that knowledge is a complex phenomenon and $\mathrm{KM}$ is a function of personal and social characteristics of the knowledge. We hope that the introduction of the new concept of KI provides new insights into the complexity of knowledge and $\mathrm{KM}$ in organizations.

\section{References}

[1] Roth, J. (2003). Enabling knowledge creation: Learning from an R\&D organization. Journal of Knowledge Management, 7(1), 32-48.

[2] Intezari, A., \& Pauleen, D. J. (2017). The past-present-future conundrum: Extending time-bound knowledge. International Journal of Knowledge Management, 13(1), 1-15.

[3] Balmisse, G., Meingan, D., \& Passerini, K. (2007). Technology Trends in Knowledge Management Tools. International Journal of Knowledge Management, 3(2), 118-131.

[4] Kimmerle, J., Cress, U., \& Held, C. (2010). The interplay between individual and collective knowledge: technologies for organisational learning and knowledge building. Knowledge Management Research \& Practice, 8(1), 33-44.

[5] Young, M., Kuo, F., \& Myers, M. D. (2012). To share or not to share: a critical research perspective on knowledge management systems. European Journal of Information Systems, 21(5), 496-511.

[6] Bou-Llusar, J. C., \& Segarra-Ciprés, M. (2006). Strategic knowledge transfer and its implications for competitive advantage: an integrative conceptual framework. Journal of Knowledge Management, 10(4), 100-112.

[7] Halawi, L. A., McCarthy, R. V, \& Aronson, J. E. (2006). Knowledge management and the competitive strategy of the firm. The Learning Organization, 13(4), 384-397.

[8] Handzic, M. (2011). Integrated socio-technical knowledge management model: an empirical evaluation. Journal of Knowledge Management, 15(2), 198-211.

[9] Ackoff, R. L. (1989). From data to wisdom. Journal of Applied Systems Analysis, 16(1), 3-9.

[10] Finestone, N., \& Snyman, R. (2005). Corporate South Africa: Making multicultural knowledge sharing work. Journal of Knowledge Management, 9(3), 128-141.

[11] Ponelis, S., \& Fairer-Wessels, F. A. (1998). Knowledge management: A literature overview. Journal of Library and Information Science, 66(1), 1-9.

[12] Davenport, T. H., \& Prusak, L. (1998). Working knowledge: How organizations manage what they know. Boston: Harvard Business School Press.

[13] Hassell, L. (2007). A continental philosophy perspective on knowledge management. Information Systems Journal, 17(2), 185-195.

[14] Kemmis, S. (1985). Action research and the politics of reflection. In D. Boud, R. Keogh, \& D. Walker (Eds.), Reflection: Turning Experience into Learning (pp. 139163). London, UK: RoutledgeFalmer.

[15] Zhang, W. J., Wang, J. W., \& Lin, Y. (2019). Integrated design and operation management for enterprise systems. Enterprise Information Systems, 13(4), 424-429.

[16] Xu, L., Wang, C., Luo, X., \& Shi, Z. (2006). Integrating knowledge management and ERP in enterprise information systems. Systems Research and Behavioral Science, 23(2), 147-156.

[17] Hendricks, K. B., Singhal, V. R., \& Stratman, J. K. (2007). The impact of enterprise systems on corporate performance: a study of ERP, SCM, and CRM system implementations. Journal of Operation Management, 25(1), 65-82.

[18] Pee, L. G. (2018). Affordances for sharing domain-specific and complex knowledge on enterprise social media. International Journal of Information Management, 43(May), 25-37.

[19] Bolloju, N., Khalifa, M., \& Turban, E. (2002). Integrating knowledge management into enterprise environments for the next generation decision support. Decision Support Systems, 33(2), 163-176.

[20] Li, Z., Wang, W. M., Liu, G., Liu, L., He, J., \& Huang, G. Q. (2018). Toward open manufacturing a crossenterprises knowledge and services exchange framework based on blockchain and edge computing. Industrial Management and Data Systems, 118(1), 303-320.

[21] Cetto, A., Klier, M., Richter, A., \& Zolitschka, J. F. (2018). "Thanks for sharing"-Identifying users' roles based on knowledge contribution in Enterprise Social Networks. Computer Networks, 135, 275-288.

[22] Lin, C., Wu, J.-C., \& Yen, D. C. (2012). Exploring barriers to knowledge flow at different knowledge management maturity stages. Information \& Management, 49(1), 10-23.

[23] Auernhammer, J., \& Hall, H. (2014). Organizational culture in knowledge creation, creativity and innovation: Towards the Freiraum model. Journal of Information Science, 40(2), 154-166. 
[24] Koh, S. C. L. (2006). A knowledge management approach for managing uncertainty in manufacturing. Industrial Management \& Data Systems, 106(4), 439-459.

[25] Newman, B., \& Conrad, K. W. (2000). A framework for characterizing knowledge management methods, practices and technologies. The Data Administration Newsletter, 2008.

[26] Walczak, S. (2005). Organizational knowledge management structure. The Learning Organization, 12(4), 330-339.

[27] Prez Lopez, S., Montes Peon, J. M., \& Vazquez Ordaz, C. J. (2004). Managing knowledge: The link between culture and organizational learning. Journal of Knowledge Management, 8(6), 93-104.

[28] Grant, R. M. (2002). Contemporary strategy analysis: Concepts, techniques and applications (4th ed.). Boston, MA: Blackwell Publishers.

[29] Ruggles, R. (1998). The state of the notion: Knowledge management in practices. California Management Review, 40(3), 80-89.

[30] Krogh, G. V., Nonaka, I., \& Nishiguchi, T. (Eds.) (2000). Knowledge creation, a source of value. London: Macmillan Press.

[31] Bhatt, G. D. (2001). Knowledge management in organisations: Examining the interaction between technologies, technique and people. Journal of Knowledge Management, 5(1), 68-75.

[32] Bourdreau, A., \& Couillard, G. (1999). Systems integration and knowledge management. Information Systems Management, 16(4), 24-32.

[33] Zeleny, M. (2006). From knowledge to wisdom: On being informed and knowledgeable, becoming wise and ethical. International Journal of Information Technology \& Decision Making, 5(4), 751-762.

[34] O'Dell, C., \& Grayson, J. C. (2003). Identifying and transferring internal best practices. In C. W. Holsapple (Ed.), Handbook on Knowledge Management (Vol. 1). NewYork, NY: Springer.

[35] Martensson, M. (2000). A critical review of knowledge management as a management tool. Journal of Knowledge Management, 4(3), 204-216.

[36] Van Beveren, J. (2002). A model of knowledge acquisition that refocuses knowledge management. Journal of Knowledge Management, 6(1), 18-22.

[37] Melkas, H., \& Harmaakorpi, V. (2008). Data, information and knowledge in regional innovation networks: Quality considerations and brokerage functions. European Journal of Innovation Management, 11(1), 103-124.

[38] Intezari, A., \& Gressel, S. (2017). Information and reformation in KM systems: big data and strategic decisionmaking. Journal of Knowledge Management, 21(1), 71-91.

[39] Weinreich, P. (2003). Identity exploration: Theory into practice. In P. Weinreich \& W. Saunderson (Eds.), Analysing identity: Cross-cultural, societal and clinical contexts (pp. 77-110). East Sussex: Routledge.

[40] Hicks, R. C., Dattero, R., \& Galup, S. D. (2006). The fivetier knowledge management hierarchy. Journal of Knowledge Management, 10(1), 19-31.

[41] Miller, B., Malloy, M. A., Masek, E., \& Wild, C. (2001). Towards a framework for managing the information environment. Information Knowledge Systems Management, 2(4), 359-384.

[42] Galup, S., Dattero, R., \& Hicks, R. (2003). The enterprise knowledge dictionary. Journal of Knowledge Management and Research Practice, 1(2), 95-101.

[43] Lillrank, P. (2003). The quality of information. International Journal of Quality \& Reliability Management, 20(6), 691-703.

[44] Firestone, J. M. (2003). Enterprise information portals and knowledge management. Massachuset: ButterworthHeinemann.

[45] Crotty, M. (1998). The foundations of social research: Meaning and perspective in the research process. St Leonards, NSW: Sage.

[46] Cohen, L., Manion, L., \& Morrison, K. (2002). Research Methods in Education. New York, NY: Routledge.

[47] Frické, M. (2009). The knowledge pyramid: A critique of the DIKW hierarchy. Journal of Information Science, 35, 131-142.

[48] Wognin, R., Henri, F., \& Marino, O. (2012). Data, information, knowledge, wisdom: A revised model for agents-based knowledge management systems. In L. Moller, L. \& J. B. Huett (Eds.), The next generation of distance education: Unconstrained learning (pp. 181-189). New York: Springer.

[49] Jennex, M. E., \& Bartczak, S. E. (2013). A revised knowledge pyramid. International Journal of Knowledge Management, 9(3), 19-30.

[50] Markus, M. (2001). Toward a theory of knowledge reuse: Types of knowledge reuse situations and factors in reuse success. Journal of Management Information Systems, 18(1), 57-93.

[51] Polanyi, M. (1966). The tacit dimension. London: Routledge \& Kegan Paul.

[52] Roberts, J., \& Armitage, J. (2008). The ignorance economy. Prometheus, 26(4), 335-354.

[53] Kurtus, R. (2002). Epistemology: The Philosophy of knowledge. Retrieved June 22, 2011, from: http://www.school-fchampions.com/knowledge/epistemology.htm.

[54] Nagel, J. (2000). The empiricist conception of experience. Philosophy, 75(3), 345-376.

[55] Alavi, M., \& Leidner, D. E. (1999). Knowledge management systems: Issues, challenges and benefits. Communications of the Association for Information Systems, 1(7), 2-36.

[56] Choo, C. W. (1998). The Knowing Organization: How organizations use information to construct meaning, create knowledge, and make decisions. New York, NY: Oxford University Press.

[57] Matthew, C. T., \& Sternberg, R. J. (2009). Developing experience-based (tacit) knowledge through reflection. Learning and Individual Differences, 19(4), 530-540.

[58] Mumford, M. D., Zaccaro, S. J., Harding, F. D., Jacobs, O. T., \& Fleishman, E. A. (2000). Leadership skills for a changing world: Solving complex social problems. The Leadership Quarterly, 11(1), 11-36.

[59] Effken, J. A. (2001). Informational basis for expert intuition. Journal of Advanced Nursing, 34(2), 246-255.

[60] Evans, J. S. B. T. (2012). Spot the difference: Distinguishing between two kinds of processing. Mind \& Society, 11(1), 121-131.

[61] Baggini, J., \& Fosl, P. S. (2007). The ethics toolkit: A compendium of ethical concepts and methods. Malden: Blackwell Publishing.

[62] Klein, G. (2015). A naturalistic decision making perspective 
on studying intuitive decision making. Journal of Applied Research in Memory and Cognition, 4(3), 164-168.

[63] Nyatanga, B., \& Vocht, H. D. (2008). Intuition in clinical decision-making: A psychological penumbra. International Journal of Palliative Nursing, 14(10), 492-496.

[64] Volz, K. G., \& Cramon, D. Y. (2006). What neuroscience can tell about intuitive processes in the context of perceptual discovery. Journal of Cognitive Neuroscience, 18(12), 2077-2087.

[65] Gigerenzer, G., Hoffrage, U., \& Goldstein, D. G. (2008). Fast and frugal heuristics are plausible models of cognition: Reply to Dougherty, Franco-Watkins, and Thomas. Psychological Review, 115(1), 230-237.

[66] Guba, E. G., \& Lincoln, Y. S. (1994). Competing paradigms in qualitative research. In N. K. Denzin \& Y. S. Lincoln (Eds.), Handbook of Qualitative Research (pp. 105-117). Thousand Oaks, CA: Sage.

[67] Intezari, A., \& Pauleen, D. J. (2014). Management Wisdom in Perspective: Are You Virtuous Enough to Succeed in Volatile Times? Journal of Business Ethics, 120(3), 393-404.

[68] Bandura, A. (1977). Social Learning Theory. Englewood Cliffs, NJ: Prentice Hall.

[69] Jarvis, P., Holford, J., \& Griffin, C. (2003). The theory \& practice of learning. London, UK: Kogan Page.

[70] Maxine, R., \& Geraldine, O. H. (2000). Knowledge management practices within a knowledge-intensive firm: The significance of the people management dimension. Journal of European Industrial Training, 24(2/3/4), 241-253.

[71] Schein, E. H. (1985). Defining organizational culture. Classics of Organization Theory, 3, 490-502.

[72] Intezari, A., Taskin, N., \& Pauleen, D. J. (2017). Looking beyond knowledge sharing: An integrative approach to knowledge management culture. Journal of Knowledge Management, 21(2), 492-515.

[73] Park, H., Ribière, V., \& Schulte, W. D. (2004). Critical attributes of organizational culture that promote knowledge management technology implementation success. Journal of Knowledge Management, 8(3), 106-117.

[74] Hofstede, G. (1984). Culture's consequences: International differences in work-related values. Newbury Park, CA: Sage.

[75] Nonaka, I., \& Konno, N. (1998). The concept of "Ba": Building a foundation for knowledge creation. California Management Review, 40(3), 40-54.

[76] Nonaka, I., \& Toyama, R. (2003). The knowledgecreating theory revisited: knowledge creation as a synthesizing process. Knowledge Management Research \& Practice, 1(1), 2.

[77] Nonaka, I., Toyama, R., \& Konno, N. (2000). SECI, ba and leadership: a unified model of dynamic knowledge creation. Long Range Planning, 33(1), 5-34.

[78] Dougherty, D. (1992). Interpretive barriers to successful product innovation in large firms. Organization Science, 3(2), 179-202.

[79] Cabrera, E. F., \& Cabrera, A. (2005). Fostering knowledge sharing through people management practices. International Journal of Human Resource Management, 16(5), 720-735.

[80] Faniel, I. M., \& Majchrzak, A. (2007). Innovating by accessing knowledge across departments. Decision
Support Systems, 43(4), 1684-1691.

[81] Douglas, M. (1987). How institutions think. London, UK: Routledge and Kegan Paul.

[82] Henderson, K. A. (2011). Post-positivism and the pragmatics of leisure research. Leisure Sciences, 33(4), 341-346.

[83] Ryan, A. B. (2006). Post-positivist approaches to research. In M. Antonesa, H. Fallon, B. Ryan, A. Ryan, T. Walsh, \& L. Borys (Eds.), Researching and writing your thesis: A guide for postgraduate students (pp. 12-28). Maynooth, Ireland: MACE, National Unive.

[84] Trochim, W. M. K. (2006). Positivism \& Post-Positivism. Retrieved from Web Center for Social Research methods website: https://socialresearchmethods.net/kb/positvsm.php

[85] Langley, A. (2007). Process thinking in strategic organization. Strategic Organization, 5(3), 271-282.

[86] Pantzar, E. (2000). Knowledge and wisdom in the information society. Foresight, The Journal of Future Studies, Strategic Thinking and Policy, 2(2), 230-236.

[87] Maglitta, J. (1995). Smarten Up! Computerworld, 29(23), 84-86.

[88] Baggini, J., \& Fosl, P. S. (2007). The ethics toolkit: A compendium of ethical concepts and methods. Malden: Blackwell Publishing.

[89] Carley, K. (1986). Knowledge acquisition as a social phenomenon. Instructional Science, 14(3), 381-438.

[90] Carter, M., \& Grover, V. (2015). Me, My Self, and I(T): Conceptualizing Information Technology Identity and its Implications. MIS Quarterly, 39(4), 931-957.

[91] Pauleen, D. J. (2017a). Dave Snowden on KM and big data/analytics: interview with David J. Pauleen. Journal of Knowledge Management, 21(1), 12-17.

[92] Stary, C. (2014). Non-disruptive knowledge and business processing in knowledge life cycles - aligning value network analysis to process management. Journal of Knowledge Management, 18(4), 651-686.

[93] Nonaka, I., \& Takeuchi, H. (1995). The knowledgecreating company. Oxford: Oxford University Press.

[94] Sivan, Y. (2000). Tips for building knowledge infrastructures. WebNet Journal, 1(4), 12-44.

[95] McDermott, R., \& O’Dell, C. (2001). Overcoming cultural barriers to sharing knowledge. Journal of Knowledge Management, 5(1), 76-85.

[96] Pauleen, D. J. (2017b). Davenport and Prusak on KM and big data/analytics: Interview with David J. Pauleen. Journal of Knowledge Management, 21(1), 7-11.

[97] Raudeliūnienè, J. ., \& Eidutè-Kavaliauskienè, I. (2016). Editorial: Special issue on knowledge management: Theory and practice in SMEs. International Journal of Learning and Change, 8(3/4), 193-197.

[98] Intezari, A., \& Pauleen, D. (2018). Wisdom, Analytics and Wicked Problems: Integral Decision Making for the Data Age. London: Routledge.

[99] Burton-Jones, A., \& Grange, C. (2013). From use to effective use: A representation theory perspective. Information Systems Research, 24(3), 632-658.

[100] Bao, C., Bardhan, I. R., Singh, H., Meyer, B. A., \& Kirksey, K. (2020). Patient-provider engagement and its impact on health outcomes: A longitudinal study of patient portal use. MIS Quarterly, 44(2), 699-723. 